\section{Familial pseudoexfoliation in Gozo}

\author{
Abstract \\ Aims To describe the occurrence of \\ pseudoexfoliation in three Gozitan \\ families. \\ Methods Three families with a high \\ incidence of pseudoexfoliation were \\ identified. All members of the three families \\ who agreed to participate were interviewed \\ and underwent a full ophthalmologic \\ examination. The pseudoexfoliation \\ status was classified as present, absent, or \\ unknown. \\ Results A total of 55 individuals from three \\ separate family probands and with a \\ male : female sex ratio of $5: 4$ were examined. \\ In all, 18 had definite evidence of \\ pseudoexfoliation, 17 of them bilaterally and \\ one showing only unilateral signs. Age was \\ the main risk factor, with 18 out of the 20 \\ individuals who were over the age of 60 years \\ having pseudoexfoliation, while none of the \\ 35 who were below the age of 60 years had \\ pseudoexfoliation. The ophthalmological \\ findings varied in different families. Family I \\ had a high incidence of both cataract and \\ glaucoma, family II had mainly glaucoma, \\ while in family III all individuals had cataract \\ but none had evidence of glaucoma. The \\ first generation of these three families \\ were deceased but their hospital and \\ clinical records revealed that in all three \\ families the father was affected and \\ there was no evidence of maternal \\ involvement. \\ Conclusions In all three families, \\ pseudoexfoliation appeared to be genetically \\ transmitted as a late onset autosomal \\ dominant trait of variable expression. \\ Maternal transmission could not be confirmed \\ in these families. \\ Eye (2005) 19, 1280-1285. doi:10.1038/sj.eye.6701767; \\ published online 26 November 2004 \\ Keywords: pseudoexfoliation syndrome; \\ familial; genetics
}

${ }^{1}$ Department of Ophthalmology, St Luke's Hospital, G'Mangia, Malta

${ }^{2}$ Department of Ophthalmology, Gozo General Hospital, Gozo, Malta

${ }^{3}$ Department of Anatomy, University of Malta, Malta

Correspondence: J Grech Hardie, Department of Ophthalmology, St. Luke's Hospital, G'Mangia, Malta Tel: ++ 356 21241251; Fax: ++ 35621220949 .

E-mail: jgh@

maltanet.net

Received: 7 May 2004

Accepted: 4 October 2004

Published online:

26 November 2004

This study was presented as a poster at the Royal College of Ophthalmologists Annual Congress 2002 in

Manchester

Proprietary interests/

funding: None
J Grech Hardie ${ }^{1,2}$, F Mercieca ${ }^{1,2}$, T Fenech ${ }^{1,2}$ and

A Cuschieri ${ }^{3}$

\section{Introduction}

The features of pseudoexfoliation syndrome (PEX) were first described by Lindberg ${ }^{1}$ in 1917. Vogt $^{2}$ termed the condition 'glaucoma capsulare' and Dvorak-Theobald ${ }^{3}$ coined the term 'pseudoexfoliation of the lens capsule' to distinguish this syndrome from true exfoliation seen in glassblowers.

PEX is characterized by the deposition of fine whitish fibrillar material which histochemically resembles amyloid, predominantly in the anterior segment of the eye but also in periocular and nonocular tissues. It is the commonest cause of secondary open-angle glaucoma. Individuals with pseudoexfoliation have an increased risk of complicated cataract surgery.

PEX, although highly prevalent in people of Scandinavian heritage, has also been documented in various races and countries ${ }^{4}$ including Canada, ${ }^{5}$ the Mediterranean region, Russia, India, Japan, ${ }^{6}$ Pakistan, the Australian aborigines, ${ }^{7}$ the Navajo Indians, ${ }^{8}$ and the southern Bantu tribe of South Africa. ${ }^{9}$ It had been widely accepted that most cases of PEX occur sporadically. However, over the years, reports suggesting a possible hereditary element have increased. Damji et $a l^{10}$ reviewed the genetic and nongenetic factors that appear to be associated with the aetiology of pseudoexfoliation. Familial occurrence of the condition has been documented in many families but there is no consensus on the mode of transmission. Autosomal dominant, autosomal recessive, $\mathrm{X}$-linked, and recently mitochondrial inheritance have all been attributed to PEX. Owing to the late onset of the disease, it is often the case that the parents of patients affected with pseudoexfoliation are often deceased and their offspring are often too young to exhibit the signs and, therefore, it is difficult to find two or more generations of affected people. Consequently, confirmation of genetic transmission has been problematic. 
Table 1 Main clinical findings in the family members of the three families

\begin{tabular}{|c|c|c|c|c|c|c|c|c|}
\hline & \multicolumn{2}{|c|}{ PEX status ${ }^{\mathrm{a}}$} & \multicolumn{2}{|c|}{ Cataract $^{\mathrm{b}}$} & \multicolumn{2}{|c|}{ Glaucoma $^{\mathrm{c}}$} & \multicolumn{2}{|c|}{$A R M D^{\mathrm{d}}$} \\
\hline & $R E$ & $L E$ & $R E$ & $L E$ & $R E$ & $L E$ & $R E$ & $L E$ \\
\hline \multicolumn{9}{|c|}{ Family I } \\
\hline $\mathrm{I}: 1$ & + & + & ++ & ++ & + & + & - & - \\
\hline II:1 & + & + & ++ & + & ++ & ++ & + & + \\
\hline II:2 & + & + & ++ & + & ++ & + & - & - \\
\hline II:4 & + & + & ++ & ++ & + & ++ & - & - \\
\hline II:6 & + & + & + & ++ & - & - & - & - \\
\hline II:8 & + & + & - & + & + & + & - & - \\
\hline II:9 & + & + & ++ & + & ++ & ++ & - & - \\
\hline II:11 & + & - & + & - & - & - & - & - \\
\hline II:13 & + & + & - & - & + & + & - & - \\
\hline \multicolumn{9}{|c|}{ Family II } \\
\hline $\mathrm{I}: 1$ & + & + & $?$ & $?$ & ++ & - & $?$ & $?$ \\
\hline II:1 & $?$ & $?$ & $?$ & $?$ & + & + & $?$ & $?$ \\
\hline II:2 & + & + & + & - & +++ & +++ & - & - \\
\hline II:3 & + & + & + & - & Sx & ++ & - & - \\
\hline II:5 & + & + & + & - & +++ & +++ & - & - \\
\hline II:6 & + & + & - & - & + & + & - & - \\
\hline II:8 & $?$ & $?$ & $?$ & $?$ & $?$ & $?$ & $?$ & $?$ \\
\hline \multicolumn{9}{|c|}{ Family III } \\
\hline $\mathrm{I}: 1$ & + & + & + & + & $?$ & $?$ & $?$ & $?$ \\
\hline II:1 & $?$ & $?$ & ++ & ++ & $?$ & $?$ & $?$ & $?$ \\
\hline II:3 & + & + & ++ & ++ & - & - & - & - \\
\hline II:5 & $?$ & $?$ & ++ & ++ & $?$ & $?$ & $?$ & $?$ \\
\hline II:6 & $?$ & $?$ & ++ & ++ & $?$ & $?$ & $?$ & $?$ \\
\hline II:8 & + & + & ++ & ++ & - & - & - & - \\
\hline II:10 & + & + & ++ & ++ & - & - & - & - \\
\hline II:12 & + & + & ++ & ++ & - & - & - & - \\
\hline II:14 & $?$ & $?$ & ++ & ++ & $?$ & $?$ & $?$ & $?$ \\
\hline II:16 & + & + & ++ & + & - & - & - & - \\
\hline II:18 & + & + & + & + & - & - & - & - \\
\hline II:20 & - & - & ++ & ++ & - & - & - & - \\
\hline II:22 & - & - & ++ & + & - & - & - & - \\
\hline
\end{tabular}

${ }^{a, d}$ Pseudoexfoliation (PEX) status and ARMD, + present, - absent; ${ }^{b}$ cataract, ++ cataract surgery; + significant cataract; - no significant cataract; cglaucoma, $S_{x}$ had trabeculectomy; + to +++ number of glaucoma medications; - no glaucoma; ? unknown/not examined.

The aim of this study is to describe three cases of familial pseudoexfoliation and its associated ophthalmological features in Gozo. Gozo is the second largest of the Maltese Archipelago and has a population of 25000 inhabitants. The older generations in this island tended to be of large families, as in the three families described in this paper. This was due to the socioeconomic conditions and customs present after World War II.

\section{Materials and methods}

Three unrelated families with a high prevalence of pseudoexfoliation, who attended the general eye clinic at the Gozo General Hospital, were identified. One of the ophthalmologists liaised with an individual from each family to provide all details available about the family history and pedigrees. All family members were traced and invited for a full ophthalmic and medical review. Some individuals were living in Malta, others had emigrated a long time ago, and some were deceased. The individuals in the first generation of these families were all deceased and therefore any retrievable clinical notes were analysed.

All the members of these three families who consented to participate in the study were examined by one of the authors (FM). Apart from demographic data, we documented the visual acuity with refraction, pseudoexfoliation status, tonometry, gonioscopy, lenticular status, and fundoscopy with careful attention to disc assessment and presence of age-related macular degeneration (ARMD). Past medical history, and 
particularly a history of thyroid and cardiovascular disease, was recorded. The use of antiglaucoma medications and a history of glaucoma and cataract surgery were also noted.

The pseudoexfoliation status was classified as present or absent, with an 'unknown' status being given to those who were not examined due to lack of cooperation with the study or emigration, or to deceased individuals whose past ocular/medical history was unavailable. All individuals examined had pupillary dilatation prior to assessment of the PEX status. The criteria used to confirm the presence of PEX were: (i) the presence of a central annular disc, partial, or complete, with or without a peripheral granular zone often just visible behind a poorly dilated pupil, and (ii) PEX flakes on the lens surface, pupil margin, or corneal endothelium. In the absence of any of these clinical signs, the PEX status was documented as absent.

The glaucoma status was assessed on the basis of the presence of at least two of the following three criteria: (a) documented intraocular pressure equal to or more than $21 \mathrm{mmHg}$; (b) glaucomatous optic disc damage, that is, uneven neuroretinal rim, disc haemorrhage or enlarged/ asymmetric cup to disc ratio; (c) visual field defect, consistent with optic disc appearance and suggestive of glaucoma, that is, arcuate scotoma, nasal step, or paracentral scotoma.

The lenticular status was classified as (a) no significant lenticular opacities; (b) lenticular opacities affecting visual acuity; (c) pseudophakia; (d) aphakia.

\section{Results}

Out of the 96 members of the three families, 55 individuals were fully assessed. A total of 20 were unavailable for assessment due to emigration, nine had passed away and the remaining 14 individuals, all in their twenties, failed to turn up for their appointments on two separate occasions.

Of the 55 individuals examined, 18 had definite evidence of pseudoexfoliation. However, out of the 20 individuals over the age of 60 years, only two were negative for the presence of pseudoexfoliation. The other 35 , who were well under 60 years of age, did not exhibit signs of PEX.

The individuals of the first generation of all three families were deceased and therefore the old medical notes at the Gozo General Hospital or private clinic were extracted. From the ophthalmic records, the only consistent finding was that in all three families, the fathers of the affected individuals had severe visual problems due to glaucoma and/or cataract. The mothers in Families I and II were not documented to have any significant glaucoma or cataract, while we were unable to retrieve any ocular history of the mother in Family III.

In Family I, all eight siblings in the second generation had definite evidence of PEX, seven of which were bilateral and one was unilateral as shown in Table 1. Their ages ranged from 63 to 79 years. Five were males and three were females. Five of these individuals already had cataract surgery and six exhibited glaucoma requiring one or two types of antiglaucoma medications. Asymmetric disc cupping was observed in all of them. The eldest sib also had bilateral disciform macular degeneration.

All four sibs examined, out of the six sibs in the second generation of Family II (Table 1), had definite pseudoexfoliation. All were suffering from glaucoma for which they were using one to three antiglaucoma medications. One of them also had had a unilateral trabeculectomy. One other sib was deceased but was known to suffer from glaucoma even though we do not have any concrete evidence that it was secondary to PEX. Another sib had emigrated and the relevant medical history could not be obtained. Three of the four sibs had significant lens opacities but none of them required surgery. None of the sibs exhibited signs of age-related macular degeneration.

The 12 sibs in the second generation of Family III ranged between the ages of 65 and 87 years (Table 1). Of the eight who were examined, six had definite PEX and all eight had a history of cataracts. The remarkable feature in this family is that there was no evidence or history whatsoever of glaucoma. Of the four remaining sibs, two had emigrated and two had passed away. The common factor in all these four patients, whom we never examined, was that they all had undergone cataract surgery. There was no evidence of age-related macular degeneration in this family.

None of the third-generation individuals exhibited signs of PEX in all three families although those examined were all under the age of 50 years. Also, there was no significantly increased prevalence of thyroid or cardiovascular disease in the whole study group.

All patients included in this study were never exposed to glassblowing.

\section{Discussion}

Despite the relatively high prevalence of pseudoexfoliation in the glaucoma population, little is yet known about the pathogenesis of this syndrome. Several environmental nongenetic factors have been implicated including ultraviolet light exposure, trauma, autoimmunity, and slow virus infection. However, there is increasing evidence in favour of genetic factors even though their role remains unclear. Twin studies provided 
some evidence for the role of genetic factors. Teikari's (1987) study $^{11}$ on Finnish monozygotic and dizygotic twins demonstrated heritability of chronic open-angle glaucoma but had insufficient twin pairs with PEX to determine the heredity of the syndrome. However, studies on Icelandic monozygotic twins published by Sverisson $e t$ al $^{12}$ and more recently by Gottfredsdottir et $a l^{13}$ reported concordance for PEX in five out of eight twin pairs aged over 55 years. These studies concluded that PEX had a strong genetic element. A familial tendency has been suggested by the finding of a high frequency of PEX among relatives of affected individuals, ${ }^{14}$ estimated to be 10 times higher than the frequency of PEX in the general population ${ }^{15}$.

Damji et $a l^{5}$ and Allingham et $a l^{16}$ published a series of two-generation families, Canadian and Icelandic, respectively, affected with PEX. In their review of the genetic factors involved in the aetiology of pseudoexfoliation, both authors observed that nearly all two-generation families reported in the literature showed evidence of maternal transmission. They proposed that although X-linked or autosomal inheritance with genomic imprinting were possible explanations, mitochondrial inheritance was the most likely mode of transmission that could also account for the variable phenotypes and nonconcordance in identical twins. However, in both published studies, the pseudoexfoliation status in the father of all 16 families together was unknown due to either death or lack of availability.

The families presented here provide strong evidence that genetic factors play a major role in the aetiology of PEX. The main problem in performing genetic studies is the late onset and the absence of symptoms until the PEX is associated with cataract or glaucoma. It is therefore quite uncommon to find a living parent of an individual with PEX. Besides, since PEX can remain undiagnosed, available medical records of deceased individuals may not be conclusive in determining the PEX status, possibly resulting in false negatives. Additionally, the progeny of the affected individuals are usually too young to exhibit signs of PEX. This makes it really difficult to construct extended pedigrees. In our three families, we had reliable evidence documented by a previous ophthalmologist, and confirmed by the second-generation individuals, that all respective fathers had visual difficulties due to glaucoma/cataract while the mothers had no significant eye disease.

Our three pedigrees (Figure 1) do not support the concepts of mitochondrial or X-linked inheritance, but strongly suggest autosomal dominant inheritance with transmission through the father. Although it may be argued that the mothers were not examined, the family history and ophthalmic records are quite categorical that there was no evidence of any eye problems in the mother, and so mitochondrial inheritance is highly unlikely. The most striking feature in our three families is that, with the exception of Family III, all the available second generations were affected with PEX. Furthermore, the two individuals in Family III who were negative for PEX were the 'youngest' of the family, both being under 70 years of age. Therefore, one can argue that these may yet exhibit the disease at a later stage in their life. Such a high prevalence among sibs, far in excess of the $50 \%$ expected in autosomal dominant traits, suggest that other factors, possibly environmental ones, might also be involved. Another possibility to be considered is that the fathers in Families I and II might have been homozygotes, but there is no evidence to shed light on this hypothesis.

The possibility of autosomal dominant inheritance as a mode of transmission had been suggested previously. Tarkkanen ${ }^{17}$ and Tarkkanen et al ${ }^{18}$ presented various families in which pseudoexfoliation, glaucoma, and myopia occurred in various members of two generations. Although there was no consistent pattern of inheritance, it was clear that genetic factors played an important role and that there was a great variability in the clinical manifestations. They suggested that the inheritance pattern was compatible with autosomal dominant inheritance with reduced penetrance. Aasved ${ }^{15}$ presented four families with PEX in two generations, suggesting a dominant trait. Ceisler et $a l^{19}$ reported a pedigree with a mother/son pair and mother's first cousin affected with PEX and they felt that this constituted sufficient evidence to suggest an autosomal dominant trait with high penetrance. In a large study involving 30 multiplex families Orr et al, ${ }^{20}$ again concluded that the syndrome appears to be an autosomal dominant trait of late onset and incomplete penetrance.

The absence of PEX in the third generation of all our three pedigrees was most probably due to the age factor and did not allow us to draw conclusive evidence of autosomal dominant inheritance, although dominant inheritance is very likely.

The expression of PEX seemed to vary considerably among the three families. While Family III exhibited mainly cataract with none suffering from glaucoma, Family II had pseudoexfoliative glaucoma as the main eye disease. On the other hand, Family I suffered from both glaucoma and cataract. These observations suggest that PEX could be clinically and genetically heterogeneous. The apparently conflicting evidence in favour of mitochondrial and autosomal inheritance suggests that PEX might be a common manifestation of different genetic disorders.

The occurrence of three families with a total of 18 affected individuals in a small island with an elderly 


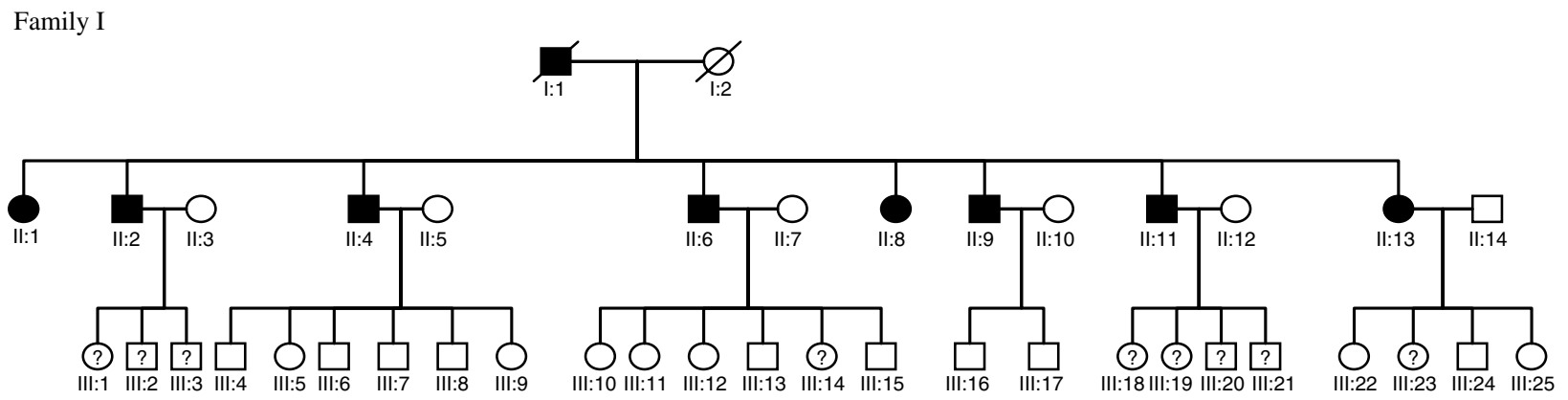

Family II

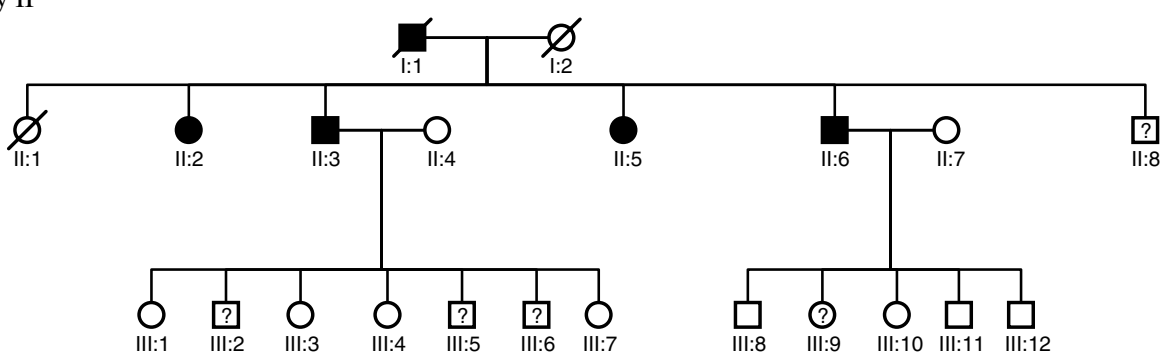

Family III

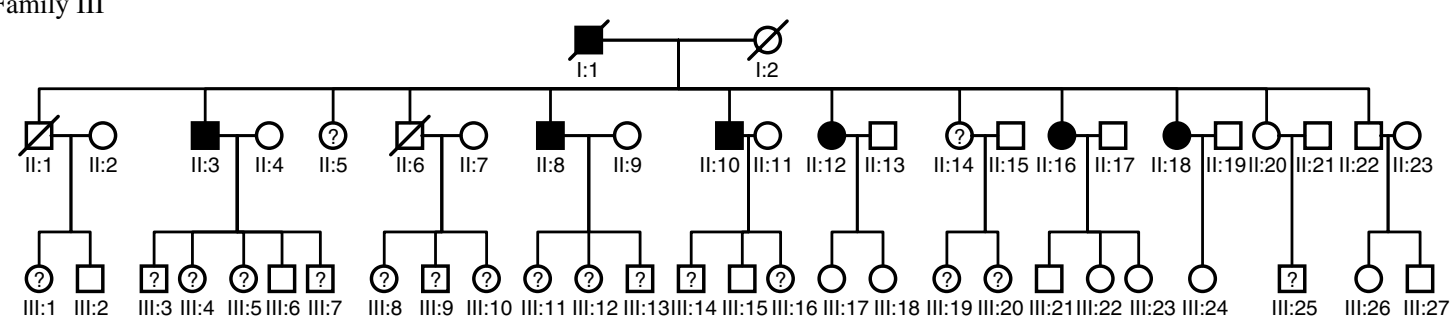

Figure 1 Pedigrees of the three Gozitan families with PEX. Squares indicate males and circles females. Black squares or circles indicate affected persons and white squares or circles unaffected persons. '?' within a square or circle indicates an unexamined individual. Single lines show nonconsanguineous marriages and slashed squares and circles show deceased individuals.

population of around 3500 suggests that the prevalence of this condition in the Maltese Islands is quite high. The ophthalmologist who identified the three families attributes the familial finding to the fact that he himself is a Gozitan and that with the culture and small size of the Gozitan community, people are known to one another. Gozo, being a small island of $5 \times 10$ miles and having a relatively stable population with a minor element of migration, which has dwindled over the past 2 decades, lends itself to a systematic study of genetic diseases, and may provide the opportunity for a thorough investigation of the genetic factors involved in pseudoexfoliation in this community. All individuals from the three families studied are being included in a genetic study, which is currently under way in an attempt to find the gene locus responsible for the PEX. A large prevalence study of the Maltese Islands has also been embarked upon.

\section{References}

1 Lindberg JG. Kliniska undersokningar over dipigmentering av pupillarranden odr genomlysbarhet av iris vid fall av alderstarr samt I normala ogon hos gamla personer. MD Thesis. Inaug Diss Helsingfors 1917.

2 Vogt A. Ein neues spaltlampenbild des pupillengebiets: hellblauer pupillensaumfilz mit hautchenbildung auf der linsenvorderkapsel. Klin Monatsbl Augenheilkd 1925; 75: $1-12$.

3 Dvorak-Theobald G. Pseudoexfoliation of the lens capsule: relation to 'true' exfoliation of the lens capsule as reported in the literature and role in its production of glaucoma capsulocuticulare. Am J Ophthalmol 1954; 37: 1-12.

4 Aasved H. The geographical distribution of fibrillopathia epiteheliocapsularis, so-called senile exfoliation or pseudoexfoliation of the anterior lens capsule. Acta Ophthalmol 1969; 47: 792.

5 Damji KF, Bains HS, Amjadi K, Dohadwala AA, Valberg JD, Chevrier $\mathrm{R}$ et al. Familial occurrence of pseudoexfoliation in Canada. Canad J Ophthalmol 1999; 34: 257-265. 
6 Mizumo K, Muroi S. Cycloscopy of pseudoexfoliation. Am Ophthalmol 1979; 87: 513.

7 Taylor HR, Hollows FC, Mann D. Pseudoexfoliation of the lens in Australian aborigines. Br J Ophthalmol 1977; 61: 473.

8 Faulkner HW. Pseudoexfoliation of the lens among the Navajo Indians. Am J Ophthalmol 1071; 72: 206.

9 Bartholomew RS. Pseudocapsular exfoliation in the Bantu of South Africa. II. Occurrence and prevalence. Br J Ophthalmol 1973; 57: 41.

10 Damji KF, Bains HS, Stefansson E, Loftsdottir M, Sverisson $\mathrm{T}$, Thorgeirsson $\mathrm{E}$ et al. Is pseudoexfoliation inherited? A review of genetic and nongenetic factors and a new observation. Ophthalmic Genet 1998; 19: 175-185.

11 Teikari JM. Genetic factors in open-angle (simple and capsular) glaucoma. A population based twin study. Acta Ophthalmol 1987; 65: 715-720.

12 Sverisson T, Gottfredsdottir MS, Stefansson E. Chronic open angle glaucoma in monozygotic twins and their spouses. Invest Ophthalmol Vis Sci 1994; 35(4): 1471

13 Gottfredsdottir MS, Sverisson T, Musch DC, Stefansson E. Chronic open angle glaucoma and associated ophthalmic findings in monozygotic twins and their spouses in Iceland. J Glaucoma 1999; 8: 134-139.
14 Pohjanpelta P, Hurskainen L. Studies on relatives of patients with glaucoma simplex and patients with pseudoexfoliation of the lens capsule. Acta Ophthalmol (Copenh) 1972; 50: 255-261.

15 Aasved H. Study of relatives of persons with fibrillopathia epitheliocapsularis (pseudoexfoliation of the lens capsule). Acta Ophthalmol 1975; 53: 879-885.

16 Allingham RR, Loftsdottir M, Gottfredsdottir MS, Thorgeirsson E, Jonasson F, Sverisson T et al. Pseudoexfoliation syndrome in Icelandic families. $\mathrm{Br} J$ Ophthalmol 2001; 85: 702-707.

17 Tarkkanen AHA. Pseudoexfoliation of the lens capsule. Acta Ophthalmol Suppl (Copenh) 1962; 71: 1-98.

18 Tarkkanen AHA, Viopio H, Koivusalo P. Family study of pseudoexfoliation and glaucoma. Acta Ophthalmol (Copenh) 1965; 43: 679-683.

19 Ceisler EJ, Sporn C Paglinauan C, Wiggs JL. Inheritance of pseudoexfoliation: evidence for autosomal dominant transmission. Invest Ophthalmol Vis Sci 1994; 35(4): 1471.

20 Orr AC, Robitaille JM, Price PA, Hamilton JR, Falvey DM, De Saint-Sardos AG et al. Exfoliation syndrome: clinical and genetic features. Ophthalmic Genetics 2001; 22: 171-185. 